\title{
Mortality and cause of death in Down's syndrome
}

\author{
R BALARAJAN, ${ }^{12}$ S P B DONNAN, ${ }^{1 *}$ AND A M ADELSTEIN† \\ From the Department of Community Medicine, ${ }^{1}$ University of Southampton, Southampton, and Medical \\ Statistics Division. ${ }^{2}$ Office of Population Censuses and Surveys, London, UK
}

SUMmaRY Mortality in sufferers from Down's syndrome over the age of 1 year in the 1970s was analysed using the Wessex Mental Handicap Register linked to the NHS Central Register. Of the 1045 subjects, 37 died during the period of the study; the standardised mortality ratio based on England and Wales mortality was 5.39. Mortality ratios were high between the ages of 1 and 14 compared with older ages. Bronchopneumonia and congenital heart disease were the main causes of death. Problems with certification and selection of underlying cause of death showed the potential value of multiple-cause coding.

In the 1950s mortality among infants with Down's syndrome was high and accounted for up to $50 \%$ of all such deaths, ${ }^{12}$ and overall mortality rates among patients with Down's syndrome have been shown to be higher than those in the general population. ${ }^{34}$ Those with Down's syndrome, however, now live much longer than they did in the $1950 \mathrm{~s}^{5-7}$

Analysis of age-specific mortality in the study of Forssman and Akesson in $1965^{\circ}$ showed an excess mortality in the group aged 1-5 and in those over 40 . Nevertheless, very high mortality ratios compared with the general population were shown in the age groups up to 14 years in the study of Oster $e t$ al in $1975^{\circ}$ and in the age groups up to 20 in the study of Richards and Sylvester in $1969 .{ }^{3}$ Life tables have also been constructed for patients with Down's syndrome. ${ }^{2610}$ Earlier life tables were limited to the younger age groups, though Oster $^{\circ}$ recently extended it into adult age.

The most common reported causes of death among patients with Down's syndrome have been congenital heart disease and respiratory tract infections. ${ }^{49}$

The present study examined mortality in Down's syndrome in the 1970s in a population using the Wessex Mental Handicap Register which was established in 1963. It started with a survey of mentally handicapped people in the region, which was designed both to update information on subjects identified by the survey and to include new cases notified thereafter. Children born in the 1970 s were usually admitted to the register well before they reached the age of 5 .

\section{Methods}

The cases on the Wessex Mental Handicap Register were flagged on the National Health Service Central Register (NHSCR) to obtain notification of deaths. The NHSCR receives copies of all death registrations and passed those that had been flagged to the Wessex register. We have analysed death certificates of those who died over the age of 1 year in the years 1972-8. Those recorded in the register as having Down's syndrome but not flagged at NHSCR for any reason have been excluded from the analysis. Person years at risk were calculated for eight age groups for each individual year within the period 1972-8 inclusive, using the Medical Research Council man years

Person years at risk, deaths, and mortality ratios for years 1972-8, Wessex Mental Handicap Register

\begin{tabular}{lrllr}
\hline $\begin{array}{l}\text { Age } \\
\text { groups }\end{array}$ & $\begin{array}{l}\text { Person years } \\
\text { at risk }\end{array}$ & $\begin{array}{l}\text { Expected } \\
\text { deaths }\end{array}$ & $\begin{array}{l}\text { Observed } \\
\text { deaths }\end{array}$ & $\begin{array}{l}\text { Mortality } \\
\text { ratio }\end{array}$ \\
\hline $1-4$ & 233.87 & 0.15 & 2 & 13.33 \\
$5-14$ & 2159.81 & 0.61 & 7 & 11.48 \\
$15-24$ & 2020.79 & 1.35 & 6 & 4.44 \\
$25-34$ & 1389.89 & 1.06 & 5 & 4.71 \\
$35-44$ & 459.23 & 0.83 & 3 & 3.61 \\
45.54 & 304.05 & 1.72 & 6 & 3.50 \\
$55-64$ & 47.38 & 0.69 & 7 & 10.14 \\
$65-74$ & 9.67 & 0.35 & 1 & 2.86 \\
Total & 6631.87 & 6.87 & 37 & 5.39 \\
\hline
\end{tabular}

"Present addresses: Dr SPB Donnan, Faculty of Medicine, Chinese University of Hong Kong, Shatin, New Territories, Hong Kong. tDr AM Adelstein, Department of Epidemiology and Medical Statistics, London School of Hygiene and Tropical Medicine, London. 
computing language (MYCL). ${ }^{11}$ Expected deaths were calculated for each age group using England and Wales age-specific death rates for the years in the study. Age-specific mortality ratios were calculated for each age group. A standardised mortality ratio was calculated for the group as a whole.

\section{Results}

Of the 1045 cases of Down's syndrome on the register who were flagged at NHSCR, 37 died during the study. The table shows the person years at risk, expected deaths, observed deaths, and mortality ratio for each of the eight selected age groups. The overall SMR was 5.39 (95\% confidence interval 3.78-7.42). The age-specific mortality ratios varied between $2 \cdot 9$ and $13 \cdot 3$.

Of the 37 deaths analysed, 30 had Down's syndrome on the death certificate, two had mental subnormality, and five had no indication of subnormality. The most frequent underlying cause of death was bronchopneumonia (10 deaths) followed by congenital heart disease (7) and Down's syndrome (7). Other underlying causes were myocardial degeneration (2), acute myocardial infarction (1), hiatus hernia (1), gastrointestinal bleeding (1), chronic oesophageal ulceration (1), diarrhoeal disease (1), septicaemia (1), hydrocephalus (1), Parkinsonism (1), carbon monoxide poisoning (1), and drowning (1). No deaths were attributed to cancer or leukaemia.

\section{Discussion}

This study was based on a population register for mentally handicapped children. There was some under-recording of cases at birth, especially those who died soon after, and therefore life table analysis was not attempted. For all those who entered the register and were flagged at NHSCR there were adequate measures to ensure an accurate and complete follow-up.

The overall age-adjusted mortality in our study is about 5.4 times that of the general population. The mortality ratio is highest in the $1-4$ age group, being 13 times higher than expected. The ratio was 11.5 times higher for the age group 5-14. The mortality then seems to stabilise at a lower ratio of between $3 \cdot 5$ to 4.7 times that of the general population. The exception was at ages 55-64 (ratio 10.1); this increase was not maintained in the oldest age group, but the total person years at risk over age 55 were very small.

Forssman and Akesson ${ }^{8}$ concluded that mortality was raised by only $11 \%$ in the $1-4$ age group and marginally between the ages 5-14 in their study based on the patients with Down's syndrome in Swedish institutions. They derived a ratio of the number of years that cases survived during the study to the number of years that controls of the same age could be expected to survive after the observation was started. Richards and Sylvester, however, ${ }^{3}$ in their study based on the institutionalised population in Surrey, showed a 23-fold increase in groups aged 5-9 and a fivefold increase in the groups aged over 20 . In a more recent study Oster et $l^{\vartheta}$ showed that the mortality ratio for those aged over 10 had fallen from 7.2 (1949-59) to 5.5 (1960-71) in comparison with the general population. Much higher mortality ratios for all groups were found in a study by Deaton in 1973.4 His study was based on cases selected from nine different Texas institutions and could represent a biased sample of vulnerable cases of Down's syndrome. The study by Oster $\mathrm{et}^{\mathrm{a} l^{9}}$ was based on a defined population in Denmark with measures to ensure completeness. Our study resembles the study by Oster $e a^{9}{ }^{9}$ more closely than others in that it was based on a total population.

Analysis of underlying cause of death shows bronchopneumonia (10) as a major cause followed by Down's syndrome itself (7) and congenital heart disease (7). Bronchopneumonia appeared as the cause of death in older patients and congenital heart disease in the younger. The underlying cause of death as Down's syndrome was found in all ages and was not restricted to the deaths in the younger age groups.

Nevertheless, 30 of the 37 deaths had Down's syndrome on the death certificate, though only seven had been coded as the underlying cause. Although seven other cases had, as underlying cause, congenital heart disease, another four had congenital heart disease in the first part of the death certificate. In addition to the 10 cases of bronchopneumonia, a further four were found among those coded as Down's syndrome. This illustrates the problem of certification and coding of death certificates and the difficulties in interpreting the whole picture from underlying cause alone for conditions such as Down's syndrome, and emphasises the value of multiple-cause coding of deaths ${ }^{12}$ whereby all conditions mentioned in the death certificate can be taken into account.

The whole exercise shows that health care information systems can produce useful clinical and epidemiological data.

We thank Dr Albert Kushlick, director, MRC Health Care Evaluation Research Team, for permission to use his register, Mr John Palmer, Mr Dennis Carlow, and Mrs Anne Robinson for their help, and Mr Vince Andrews, department of community medicine, Southampton University, for computing help. 
Reprints from: Dr R Balarajan, Department of Community Medicine, University of Southampton, South Academic Block, Southampton General Hospital, Southampton SO9 4XY.

\section{References}

${ }^{1}$ Record RG, Smith A. Incidence mortality and sex distribution of mongoloid defectives. Br J Prev Soc Med 1955; 9: 10-5.

${ }^{2}$ Carter CO. A life table for mongols with causes of death. $J$ Ment Defic Res 1958; 2: 64-6.

${ }^{3}$ Richards BW, Sylvester PE. Mortality trends in mental deficiency institutions. J Ment Defic Res 1969; 13: 276-92.

${ }^{4}$ Deaton JG. The mortality rate and causes of death among institutionalised mongols in Texas. $J$ Ment Defic Res 1973; 17: 117-22.
${ }^{5}$ Brothers CRD, Jago GC. Report on the longevity and the cause of death in mongoloidism in the State of Victoria. Journal of Mental Science 1954, 100: 580-6.

'Gallaher RP, Lowry RB. Longevity in Down's syndrome in British Columbia.J Ment Defic Res 1975; 19: 157-63.

${ }^{7}$ Mulcahy MT. Down's syndrome in Western Australia mortality and survival. Clin Genet 1979, 16: 103-8.

${ }^{8}$ Forssman $\mathrm{H}$, Akesson HO. Mortality in patients with Down's syndrome. J Ment Defic Res 1965; 7: 146-9.

${ }^{\circ}$ Oster J, Mikkelsen M, Neilsen A. Mortality and life tables in Down's syndrome. Acta Paediatr Scand 1975; 64: 322-6.

${ }^{10}$ Fabia J, Drolette M. Life tables up to age 10 for mongols with and without congenital heart defect. J Ment Defic Res 1970; 19: 157-63.

${ }^{11}$ Hill ID. Computing man years at risk. J Prev Soc Med 1972; 26: 132-4.

${ }^{12}$ Registrar General's Statistical review of England and Wales for the year 1966. Part III. London: HMSO, 1970. 